\title{
Wafer-level micro-structuring of glassy carbon
}

\author{
Loïc E. Hans ${ }^{1, *}$, Karin Prater ${ }^{1, *}$, Cedric Kilchoer ${ }^{1}$, Toralf Scharf ${ }^{1}$, Hans Peter Herzig ${ }^{1}$ and Andreas \\ Hermerschmidt $^{2}$ \\ ${ }^{1}$ Optics \& Photonics Technology Laboratory, École Polytechnique Fédérale de Lausanne (EPFL), \\ Neuchâtel, CH-2000, Switzerland \\ ${ }^{2}$ HOLOEYE Photonics AG, 12489 Berlin-Adlershof, Germany
}

\begin{abstract}
Glassy carbon is used nowadays for a variety of applications because of its mechanical strength, thermal stability and non-sticking adhesion properties. One application is glass molding that allows to realize high resolution diffractive optical elements on large areas and at affordable price appropriate for mass production. We study glassy carbon microstructuring for future precision compression molding of low and high glass-transition temperature. For applications in optics the uniformity, surface roughness, edge definition and lateral resolution are very important parameters for a stamp and the final product. We study different methods of microstructuring of glassy carbon by etching and milling. Reactive ion etching with different protection layers such as photoresists, aluminium and titanium hard masks have been performed and will be compare with Ion beam etching. We comment on the quality of the structure definition and give process details as well as drawbacks for the different methods. In our fabrications we were able to realize optically flat diffractive structures with slope angles of $80^{\circ}$ at typical feature sizes of 5 micron and $700 \mathrm{~nm}$ depth qualified for high precision glass molding.
\end{abstract}

Keywords: glassy carbon, reactive ion etching, ion beam etching, diffractive optical element, glass molding

\section{INTRODUCTION}

Diffractive optics is making its way into industry through a large panel of applications, ranging from bio-technology via printing, material processing, sensing and optical metrology [1,2]. Diffractive optical elements (DOEs) become key components for laser-based systems by controlling the shape of the beam [3]. Compared to their refractive counterparts such as lenses, prisms or aspheres, diffractive optics can realize almost the same optical functions, while being much thinner and lighter [4].

Glass micro optical elements are currently mainly fabricated either by using direct precision machining process or by cleanroom micromachining technologies such as photolithography and etching [5-11]. For the economical manufacturing of high-precision glass optical elements, especially when it comes to mass production and high power applications, large-area replication-based technologies such as precision compression glass molding are promising alternatives [1215]. Glass compression molding technology requires pressing a structured substrate into a glass substrate at a temperature close to the glass-transition temperature $\left(T_{g}\right)$, which is higher than $400^{\circ} \mathrm{C}$ for low $T_{g}$ glasses and becomes more than $1400^{\circ} \mathrm{C}$ for fused silica. The glass part then becomes the negative replica (reverse topography) of the mold.

Komori et al. and Yasui et al. have reviewed the characteristics of different mold materials for glass imprinting [16, 17]. Mold materials such as nickel, silicon or silicon dioxide, which are used for polymers injection molding, are not suitable for high $T_{g}$ glass compression molding because of their poor heat stability and strong adhesion when releasing the glass part from the mold. However carbide-based hard alloys, such as tungsten carbide or silicon carbide, are commonly used to mold metals and glasses [14, 18-20].

Nanostructuring the mentioned alloys is quite difficult and leads to wasting expensive fabrication material. There are other interesting candidates, as for example graphene-coated silicon, copper-nickel alloy, nickel-phosphorus and chemical vapor-deposited diamond [16, 21-23].

*loic.hans@epfl.ch; phone: +41216954279; opt.epfl.ch, and karin.prater@epfl.ch; phone: +41216954556; opt.epfl.ch 
Glassy carbon (glass-like carbon, vitreous carbon, GC) is especially interesting for compression glass molding of high $\mathrm{T}_{\mathrm{g}}$ glasses, such as fused silica. The successful use of glassy carbon as a mold has been reported a couple of times during the last decade $[24,25]$. Glassy carbon has interesting properties that are related to its fullerene-related structure and allows extreme operating temperature (up to $2000^{\circ} \mathrm{C}$ ) [26]. It is chemically inert and stable, and has a high hardness and a gas impermeability that leads to a low cohesion between glassy carbon and molding glasses [24, 27-29]. Glassy carbon can be polished and allows fabricating wafers of different sizes with high surface quality of $\lambda / 20$ (over one inch length). The major drawback is that GC cannot easily be microstructured with conventional machines. But etching techniques and milling techniques known from microfabrication have been proven to be effective for depths in the order of micrometers. Different techniques for glassy carbon micro-structuration have already been tested. Kuhnke et al. have made a comparison between direct laser micromachining and reactive ion etching (RIE) [28], and Youn et al. and Takahashi et al. have investigated focused ion beam, nano/femtosecond-pulsed laser, excimer laser and dicing techniques [24, 30-32]. Dry etching of glassy carbon which results in a smooth surface quality has been highlighted by combining $\mathrm{SF}_{6} / \mathrm{O}_{2}$ during the RIE process $[33,34]$.

For the high-throughput application of glass molding to diffractive optics, despite the mentioned advances, it is necessary to investigate large-area-compatible process flows for microstructured GC with a high optical surface quality. Such an investigation is our main target in this manuscript. We describe different process flows based on photolithography and dry etching technologies. We first show the characterization results of the plasma etching of GC through a microstructured photoresist (PR) layer at the surface of the substrate. We then compare these results with the etching of glassy carbon using either aluminium ( $\mathrm{Al}$ ) or titanium (Ti) hard masks and we describe the etching of $\mathrm{GC}$ using a broad-beam ion etcher (IBE).

\section{EXPERIMENTAL PROCEDURE}

For this study a set of diffractive optical elements have been designed. It includes two-levels phase gratings which act as beam splitters and various test structures. We defined lateral feature sizes between 5 and $10 \mu \mathrm{m}$ wide, with critical dimensions of about $2 \mu \mathrm{m}$. The active areas are between 5 and $18 \mathrm{~mm}$ in diameter. A picture of the quartz chrome $(\mathrm{Cr})$ 5 " photolithography mask used to pattern 4" glassy carbon wafers is given in Figure 1.

Different anisotropic etching techniques for glassy carbon structuring are investigated. The process flows are summarized in Figure 2. These processes are based on the use of 4" diameter double-side polished glassy carbon wafers with a thickness of $1 \mathrm{~mm}$ (substrates are AC-140 Glass Like Carbon Plate provided from Nisshinbo). The blank glassy carbon wafers delivered show a high surface quality with an average roughness $\mathrm{RMS}_{\mathrm{a}}<5 \mathrm{~nm}$.

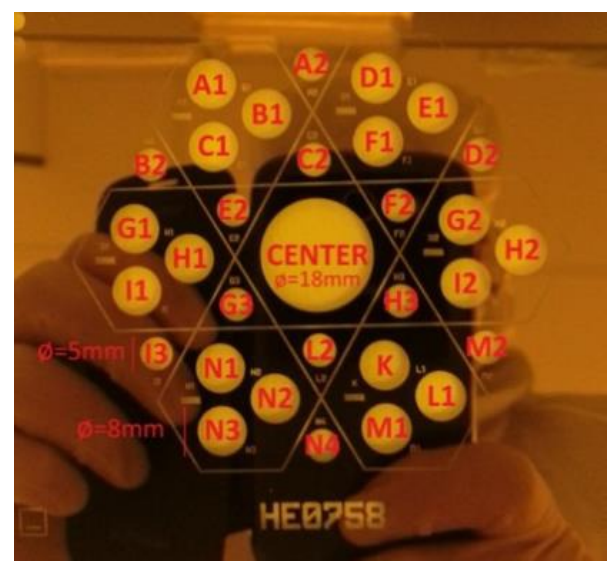

Figure 1: 5" Quartz/Cr photolithography mask with the different diffractive structures 


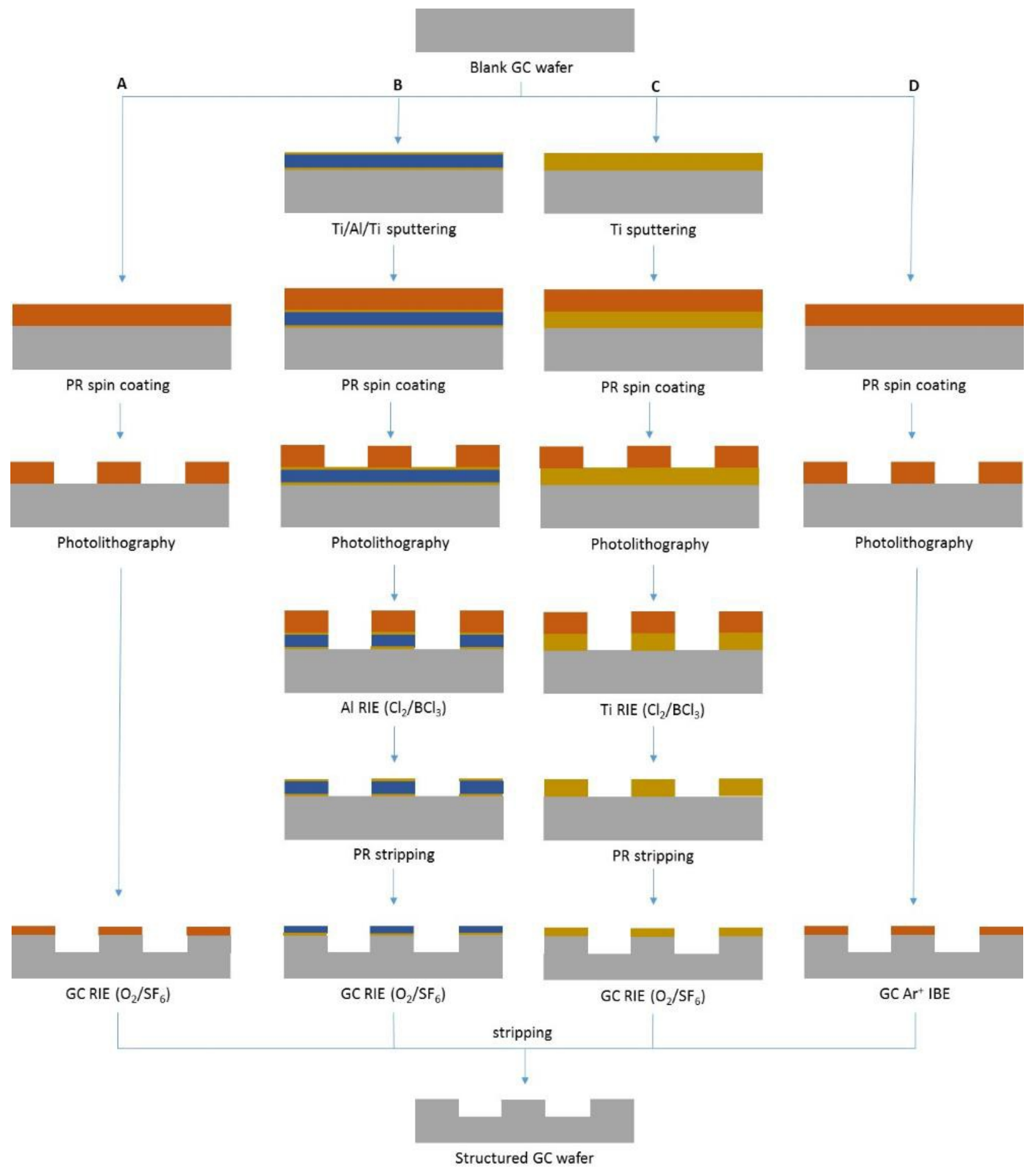

Figure 2: Overview of the four different investigated process flows (A to D). The processes are described in section 2. In section 3 a comparison between these processes with respect to their etching performance and resulting structure quality is made. 


\subsection{Glassy carbon reactive ion etching using a photoresist mask}

The described process flow is based on the deposition and structuring of a single photoresist film which is to be used as a mask for reactive ion etching of glassy carbon (Figure 2: A). To enhance adhesion of photoresist on glassy carbon, hexamethyldislazane (HMDS) is used as a primer agent. A $2.8 \mu \mathrm{m}$ positive photoresist film (MicroChemicals AZ 1518) is then deposited on the glassy carbon surface by spin coating (Convac), followed by a baking step on a hotplate for 1 min at $90^{\circ} \mathrm{C}$. The photolithography process is done by illuminating the substrate during $2 \mathrm{sec}$ with an intensity of 13 $\mathrm{mW} / \mathrm{cm}^{2}$ through the photolithography mask in the mask aligner system (Süss Microtec MA8 GEN3). The substrate and the mask are in vacuum-contact mode during exposure to assure highest spatial resolution. The development is done during $45 \mathrm{sec}$ with the remover AZ351B (MicroChemicals) in deionized water (DI). The concentration ratio between the remover and DI water is 1:4. The substrates are then rinsed and dried at $2400 \mathrm{rpm}$ for $60 \mathrm{sec}$.

For the GC etching we used an inductively coupled plasma reactive ion etching (ICP-RIE) system (SPTS Advanced Plasma System). The glassy carbon wafers are conductive enough to be held on the electrostatic chuck without requiring a backside layer deposition; the measured helium-cooling leaks are about $50 \mathrm{mTorr} / \mathrm{min}$ when the substrate lies on the chuck. The electrodes frequency (RF) are $13.56 \mathrm{MHz}$, with a coil power of $950 \mathrm{~W}$, a platen power of $100 \mathrm{~W}$, a platen chiller at $20^{\circ} \mathrm{C}$ and a chamber pressure down to $37.5 \mathrm{mTorr}$. In order to avoid micro-masking effect, the used chemistry is $\mathrm{O}_{2} / \mathrm{SF}_{6}$. The gas flow rate was 40 and $10 \mathrm{sccm}$ for $\mathrm{O}_{2}$ and $\mathrm{SF}_{6}$ respectively. The remaining photoresist at the substrate surface was then stripped by wet etching with Remover 1165 (Shipley Microposit) warmed at $70^{\circ} \mathrm{C}$ for 10 min, prior of rinsing and drying.

\subsection{Glassy carbon plasma etching using an aluminium or a titanium hard mask}

Aluminum and titanium were used as hard mask for reactive ion etching of glassy carbon (Figure 2: B and C). The fabrication steps are similar for both processes. Two thin titanium layers are sputtered before and after aluminium deposition to increase the adhesion between the aluminium hard mask and both substrate and photoresist. The metallic layer thickness is then $5 \mathrm{~nm} \mathrm{Ti} / 300 \mathrm{~nm} \mathrm{Al} / 5 \mathrm{~nm}$ Ti for process flow B, and $500 \mathrm{~nm}$ Ti for process flow C. The deposition is made on the GC wafers using a sputtering system (Alliance-Concept DP 650). This step is followed by $140^{\circ} \mathrm{C}$ thermal dehydration for $10 \mathrm{~min}$ in an oven (Bita Yes III). A positive-type resist, AZ $1512 \mathrm{HS}$ (MicroChemicals), was then spin-coated on the $\mathrm{TiO}_{2}$ surface layer (automatic coater and developer system EVG 150). This step was followed by $112^{\circ} \mathrm{C}$ baking for $1 \mathrm{~min} 30 \mathrm{sec}$ on a hot plate, resulting in a film thickness of $1 \mu \mathrm{m}$. The resist film was then exposed through the photolithography mask in hard-contact mode with an intensity of $10 \mathrm{~mW} / \mathrm{cm}^{2}$ for $1.5 \mathrm{sec}$ (Süss MicroTec MA6/BA6). The wafers were developed to remove the exposed photoresist, and rinsed into DI water.

The metallic layers were etched in an ICP-RIE system (STS Multiplex). The etching parameters used for both $\mathrm{Al}$ and $\mathrm{Ti}$ etching processes were the same. The radio frequency power on the ICP electrodes was $13.56 \mathrm{MHz}$. The coil power inducing the plasma was at $800 \mathrm{~W}$, and the platen power located below the substrate was at $150 \mathrm{~W}$, for a chamber pressure of $3 \mathrm{mTorr}$ and a platen chiller at $20^{\circ} \mathrm{C}$. The used chemistry is $\mathrm{Cl}_{2} / \mathrm{BCl}_{3}$, with a gas flow rate of $10 \mathrm{sccm}$ for both species. After hard mask layers etching, the substrates were rinsed into deionized water. This will avoid the hard mask corrosion through the creation of $\mathrm{HCl}$ that is obtained with the reaction between water vapor (coming from the cleanroom air when there is $45 \%$ or more humidity) and chlorine residues (that are remaining at the $\mathrm{Al}$ or Ti surface). The remaining PR film on the samples were then stripped on a wet bench containing two baths of Remover 1165 (Shipley Microposit) heated at $70^{\circ} \mathrm{C}$, before being rinsed and dried.

For the GC etching we used another ICP-RIE system (SPTS Advanced Plasma System). The electrodes frequency was 13.56 MHz, with a coil power of $950 \mathrm{~W}$ and a platen power of $100 \mathrm{~W}$. The chamber pressure is $37.5 \mathrm{mTorr}$. The substrate is cooled down with a platen chiller at $20^{\circ} \mathrm{C}$. The used chemistry is $\mathrm{O}_{2} / \mathrm{SF}_{6}$, with a gas flow rate of $40 \mathrm{sccm}$, respectively $10 \mathrm{sccm}$. The substrates were then stripped by wet etching, prior of being rinsed and dried in a mixture of phosphoric, acetic and nitric acids warmed at $35^{\circ} \mathrm{C}$ for $10 \mathrm{~min}$ to remove $\mathrm{Al}$, and hydrofluoric acid at room temperature for $5 \mathrm{~min}$ to remove $\mathrm{Ti}$ and $\mathrm{TiO}_{2}$ layers. To achieve a better $\mathrm{Al}$ stripping during wet etching after the RIE, it is advised to do an oxidization step using $\mathrm{O}_{2}$ plasma, which creates $\mathrm{Al}_{2} \mathrm{O}_{3}$. However as the use of $\mathrm{O}_{2}$ plasma without adding $\mathrm{SF}_{6}$ creates a rough surface for glassy carbon; this step has been put aside. 


\subsection{Glassy carbon ion beam etching using a photoresist mask}

The process described here is based on the use of a microstructured photoresist mask deposited on a glassy carbon substrate that is etched by ion beam etching (Figure 2: D). The resist deposition and photolithography processes are nearly the same as previously described in subsection 2.1; however the photoresist film is $1060 \mathrm{~nm}$ thick here.

The etching process includes the use of an ion beam etcher system (Veeco NEXUS IBE-350) based on the ions bombardment of the glassy carbon substrate. To do so, the ions are extracted by current oscillations between parallel electrodes using a RF generator from argon gas located inside the discharged chamber. $\mathrm{The} \mathrm{Ar}^{+}$ions are then accelerated by a three-grid system (molybdenum apertures separated by a distance of a few millimeters), forming a collimated and invariant energy beam that is designed to etch large surface such as 4" wafer. The glassy carbon surface was etched with a tilt angle of $5^{\circ}$ regarding the normal incidence of the ion beam while the substrate was rotating. The beam voltage was $500 \mathrm{~V}$ and its current $0.8 \mathrm{~A}$. The electric current density was $1.2 \mathrm{~mA} / \mathrm{cm}^{2}$.

\section{RESULTS AND DISCUSSIONS}

\subsection{Glassy carbon reactive ion etching using a photoresist mask}

The $\mathrm{O}_{2} / \mathrm{SF}_{6}$ process step to etch glassy carbon also etches the photoresist mask at the same time. The obtained GC etching rate is $110 \mathrm{~nm} / \mathrm{min}$, while the photoresist etching rate is $540 \mathrm{~nm} / \mathrm{min}$. The selectivity between GC and the PR mask is therefore only 1:5. This makes it very difficult to etch depth of a 1 micron into glassy carbon at very high resolution because the photoresist needs to be at least 5 micron high. Figure 3 shows the scanning electron microscopy (SEM) and white light interferometry picture (Veeco Wyko NT1100) of etching test results. Regarding the surface quality, we can see that there is no micro-masking effect with the used chemistry and etching parameters, and the structuring process provides high uniformity. The measured surface is smooth with a quite low roughness of $\mathrm{RMS}_{\mathrm{a}}<20$ $\mathrm{nm}$. The surface is well stripped, although we have not used a PR ashing-step in an $\mathrm{O}_{2}$ plasma. However the edge quality is not satisfactory which is visible by the large bright lines. Such lines indicates that the edges are not sharp. The slope angle $\alpha$ is a parameter that measures the wall verticality. This angle $\alpha$ is defined as the tangent of the etching depth divided by the projected distance between the top and the bottom of the wall. For this process flow, the slope angle is $\alpha=$ $37^{\circ}$.

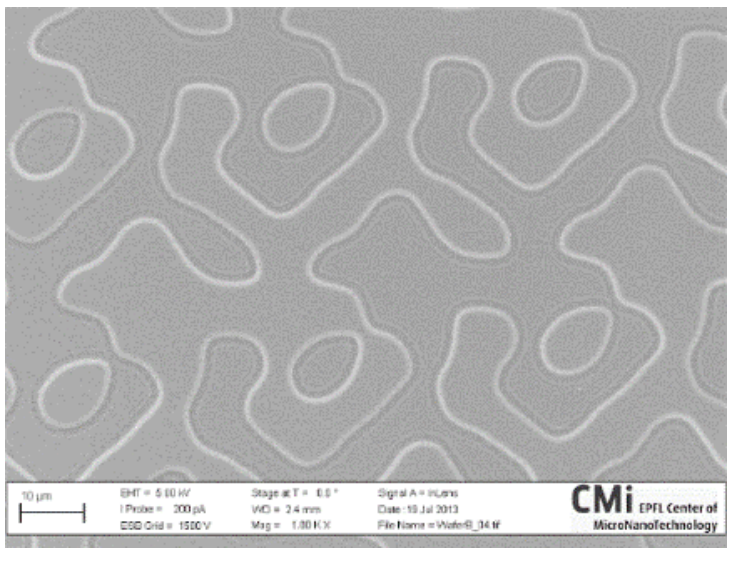

a)

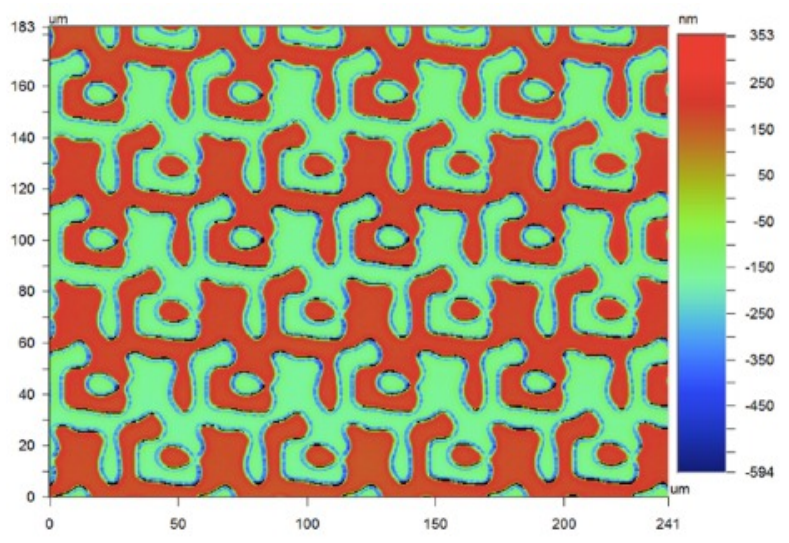

b)

Figure 3: SEM image and white light interferometer image (VSI-mode) of photoresist micro-patterned glassy carbon. The structure height is $523 \mathrm{~nm}$.

\subsection{Glassy carbon plasma etching using an aluminum hard mask}

The reactive ion etching process etched the $5 \mathrm{~nm} \mathrm{Ti} / 300 \mathrm{~nm} \mathrm{Al} / 5 \mathrm{~nm}$ Ti layers from process flow B in about 80 sec. When the non-cover metallic layers are open, a strong contrasted color change of the dedicated wafer areas can be observed. This effect is due to the glassy carbon that is much less reflective than the aluminum layer. The etching stopinstant is determined by being $20 \mathrm{sec}$ after the end of this color transition, in order to assure an uniform opening of the hard mask all over the substrate. The Al etching rate was $280 \mathrm{~nm} / \mathrm{min}$. The selectivity ratio between $\mathrm{Al}$ and the PR for 
this process is $1: 1.3$. The resist is then etched only slightly faster than the $\mathrm{Al}$. The $\mathrm{Cl}_{2} / \mathrm{BCl}_{3}$ chemistry does not react with glassy carbon. Thus the surface quality of glassy carbon is still similar to blank substrates. Figure 4 illustrates the quality of the structures with the remaining photoresist on the metallic layers and the hard mask in aluminum.

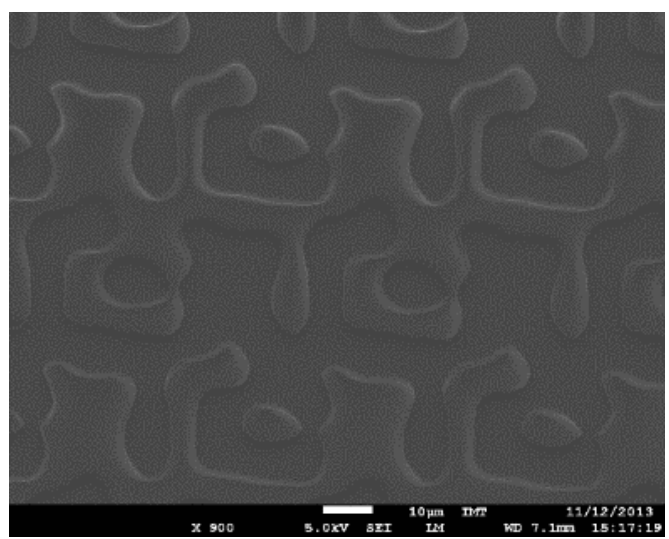

a)

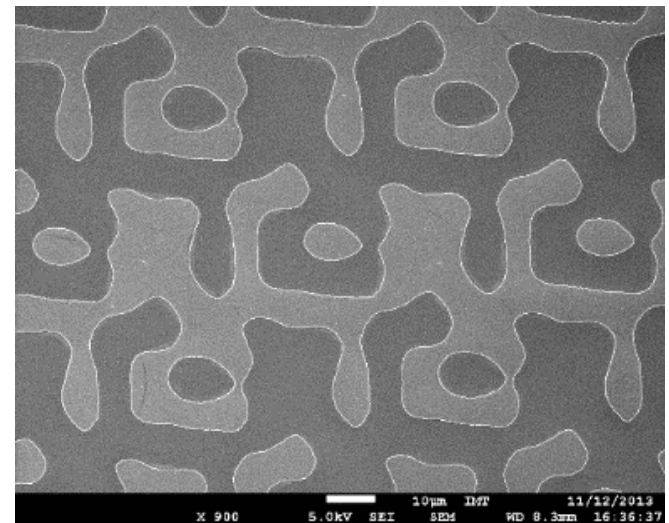

b)

Figure 4: a) A 325nm PR layer on $310 \mathrm{~nm}$ Al layer after STS RIE. Roughness of glassy carbon in the opened areas remains low because the RIE did not attacked the GC surface. b) A $310 \mathrm{~nm}$ thick Al layer after STS RIE and PR stripping.

The next step, based on the use of $\mathrm{O}_{2} / \mathrm{SF}_{6} \mathrm{RIE}$, etches the glassy carbon and the $\mathrm{Al}$ hard mask with the following results. The etching rate is $230 \mathrm{~nm} / \mathrm{min}$ and $100 \mathrm{~nm} / \mathrm{min}$ for $\mathrm{GC}$ and $\mathrm{Al}$ respectively. The related selectivity between $\mathrm{GC}$ and $\mathrm{Al}$ is then 1:0.4, meaning that aluminium is etched more than two times faster than glassy carbon. The wall verticality is $\alpha=$ $67^{\circ}$, overall very promising parameters. Looking at the structured surface in more details (as shown in Figure 5), a heavy contamination that happened during the etching step can be seen. Impurities are visible all over the glassy carbon substrates. The reason is not fully explored yet but it is assumed that non-volatile particles of aluminum compound are re-deposited and cannot be removed with conventional methods. In contrary to this unwanted deposition, one states that there is no micro-masking effect visible and roughness is acceptable (below $\mathrm{RMS}_{\mathrm{a}}<20 \mathrm{~nm}$ ) when measured in areas without re-deposition.

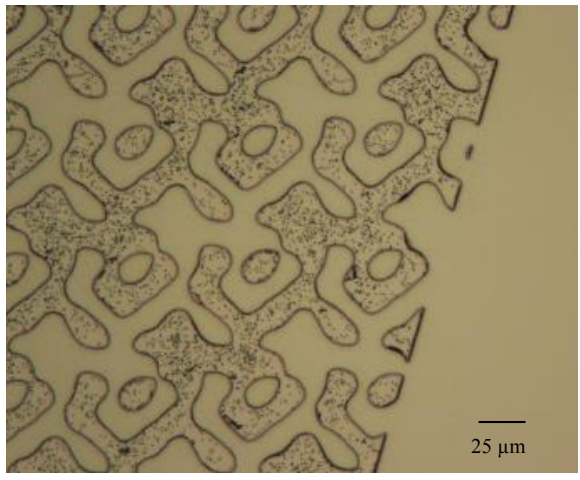

a)

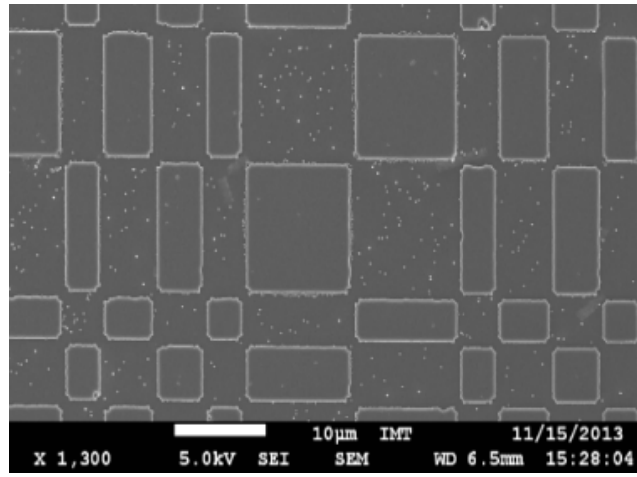

b)

Figure 5. Micrograph and SEM picture of etched glassy carbon wafer (depth $=460 \mathrm{~nm}$ ) using $\mathrm{Al}$ as hard mask. The small dots are deposition of $\mathrm{Al}$ compound of unknown nature during the etching process making the structures useless for optical applications.

\subsection{Glassy carbon plasma etching using a titanium hard mask}

The Ti etching process requires the use of a rather thick hard mask of Ti of about $500 \mathrm{~nm}$ thickness. The RIE process to open the mask and to etch the $500 \mathrm{~nm}$ Ti layer took about $140 \mathrm{sec}$ and the etching stop instant was determined $20 \mathrm{sec}$ after the end of the color change, as it has be done for Al hard mask previously. The Ti etching rate is about $210 \mathrm{~nm} / \mathrm{min}$. 
The selectivity ratio is about $1: 1$ between Ti and the photoresist. The $\mathrm{Cl}_{2} / \mathrm{BCl}_{3}$ chemistry still does not react with glassy carbon.

The particularity with $\mathrm{Ti}$ is its sensitivity to oxygen that forms a titanium oxide layer $\left(\mathrm{TiO}_{2}\right)$ when exposed to it. The result is that a thin layer of titanium oxide is present when etching starts and it is then slowly removed. The thickness of this oxide layer is in the $\mathrm{nm}$ range at ambient temperature $\left(20^{\circ} \mathrm{C}\right)$, and the grain size can vary between 20 and $100 \mathrm{~nm}$ $[35,36]$. The effect of the titanium oxide layer is twofold. It leads to a non-linear etching characteristics (the oxide has a different etching rate that the pure $\mathrm{Ti}$ ) and the grains will alter the lateral resolution. The result are still high quality $\mathrm{Ti}$ structures with high verticality as shows in Figure 6.

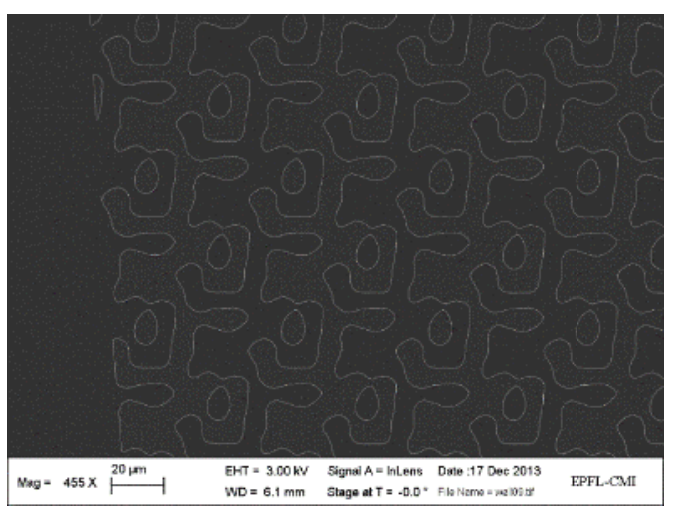

a)

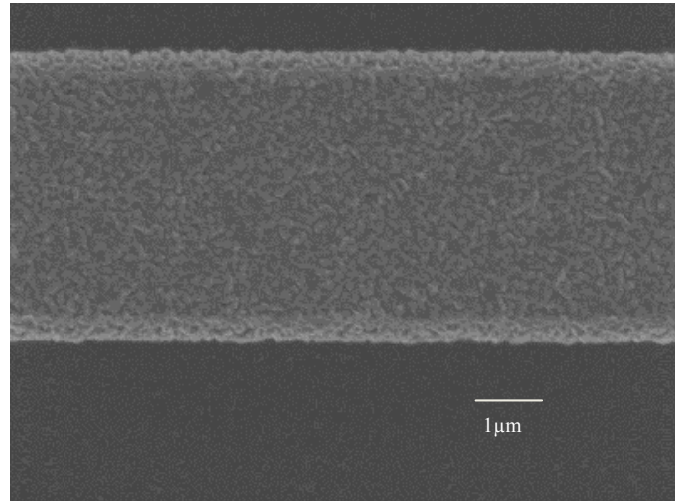

b)

Figure 6. a) High definition binary structures are shown after opening the Ti mask. b) Grains of titanium oxide are present at the Ti surface.

The etching step with $\mathrm{O}_{2} / \mathrm{SF}_{6}$ species provides an etching rate of $512 \mathrm{~nm} / \mathrm{min}$ for GC. Due to the TiO2 layer diffused at the $\mathrm{Ti}$ surface, the $\mathrm{TiO}_{2} / \mathrm{Ti}$ etching rate is non-linear. The selectivity between $\mathrm{GC}$ and $\mathrm{TiO}_{2} / \mathrm{Ti}$ vary from 1:0.2 to 1:0.5 (for GC depth of $506 \mathrm{~nm}$ to $738 \mathrm{~nm}$, and for related $\mathrm{TiO}_{2} / \mathrm{Ti}$ depth of $123-265 \mathrm{~nm}$ ). Etching deeper into GC, while removing only $\mathrm{Ti}$, increases the selectivity. $\mathrm{TiO}_{2}$ has then a smaller etching rate than $\mathrm{GC}$, and $\mathrm{Ti}$ has a higher etching rate than GC. The stripping process does not requires steps such as surface activation through $\mathrm{O}_{2}$ plasma before wet etching to obtain a nice Ti removal. The glassy carbon surface quality then shows a roughness $\mathrm{RMS}_{\mathrm{a}}<5 \mathrm{~nm}$. The wall verticality is $\alpha=79^{\circ}$. The parameters are overall very promising, as shown in Figure 7. The Figure 8 b) (Bruker Dektak XT) demonstrates the high uniformity process for $50 \mu \mathrm{m}$ large periods and over a $3.5 \mathrm{~mm}$ of length. The obtained structure depth is $506 \mathrm{~nm}$ in this case.

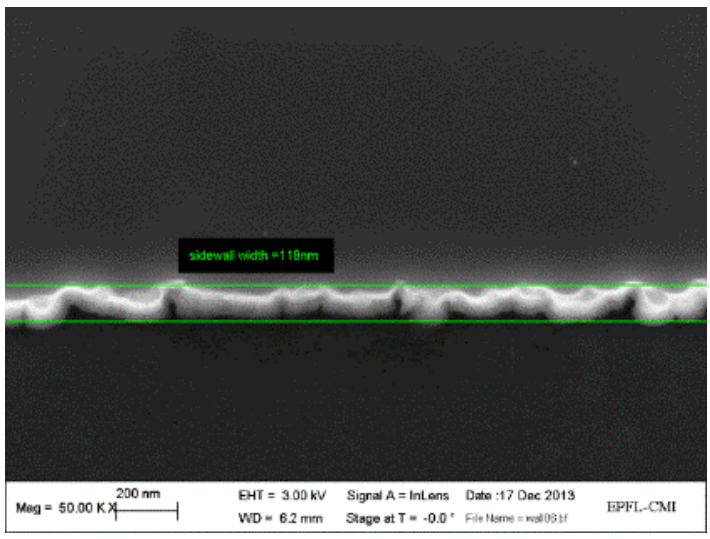

a)

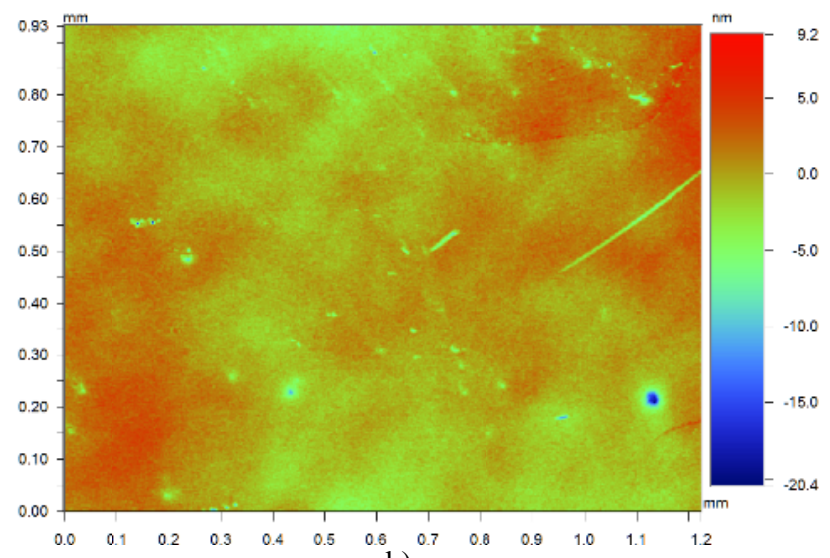

b)

Figure 7. a) Glassy carbon edges are defined with $100 \mathrm{~nm}$ width at a $506 \mathrm{~nm}$ depth. The lateral resolution fits the grains boundaries from the etched $\mathrm{TiO}_{2}$ native layer. b) Topology measurement (white light interferometer, PSI-mode) of the GC etched surface over a non-structured $1 \mathrm{~mm}^{2}$ surface. The $\mathrm{RMS}_{\mathrm{a}}$ is about $2 \mathrm{~nm}$. 


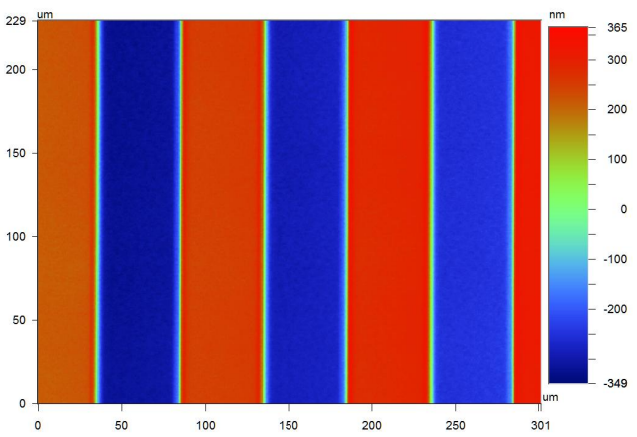

a)

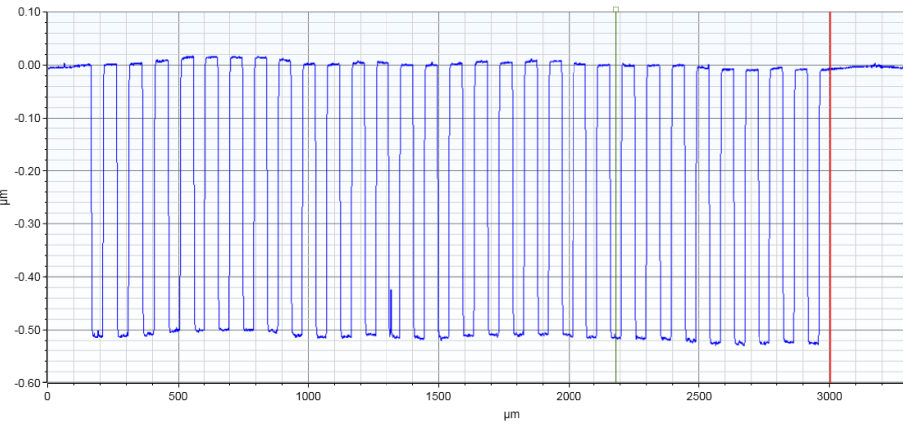

b)

Figure 8. Glassy carbon structures with $50 \mu \mathrm{m}$ period, 506nm depth and showing a high uniformity. a) White light interferometer measurement (VSI-mode). b) Mechanical profilometer measurement.

The Ti-mask process fulfils all necessary requirements for the fabrication of diffractive optical elements. However as a titanium oxide layer is present at the Ti surface, further investigation are needed to refine the process. This is especially true while etching deeper than $740 \mathrm{~nm}$ into GC. Figure 9 a) shows the final surface of an etched glassy carbon wafer. Illuminating the structures with a collimated laser beam results in the projection of the relative designed diffraction pattern.

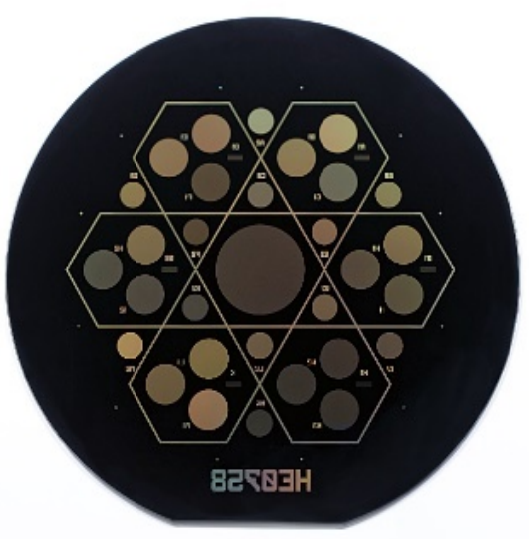

a)

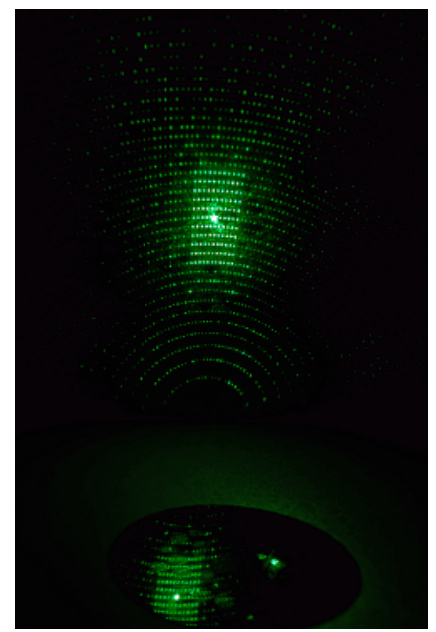

b)

Figure 9. a) Four-inches glassy carbon wafer with diffractive microstructures. The depth is $738 \mathrm{~nm}$ b) Beam splitter pattern, projected by the reflection of a green laser pointer $(\mathrm{P}=5 \mathrm{~mW}, \lambda=533 \mathrm{~nm})$.

\subsection{Glassy carbon ion beam etching using a photoresist mask}

The GC ion beam etching through the microstructured PR mask shows an etching rate of 12.3 and $30.4 \mathrm{~nm} / \mathrm{min}$ for the $\mathrm{GC}$ and the PR respectively. The selectivity between the GC and the PR is $1: 2.5$. In order to etch $1 \mu \mathrm{m}$ of GC, a $2.5 \mu \mathrm{m}$ thick layer of photoresist is required. High resolution and aspect ratio are compromised for such thick mask layer. Regarding the structure quality, after PR stripping and at an etched depth of $331 \mathrm{~nm}$, the slope angle $\alpha$ is $61^{\circ}$, and the roughness $\mathrm{RMS}_{\mathrm{a}}<15 \mathrm{~nm}$. We observe on Figure 10 that photoresist residues are still present at the surface. The ion beam milling process hardened a thin layer of photoresist. A bath of solvent Shipley 1165 at $70^{\circ} \mathrm{C}$ has been used for 20 $\mathrm{min}$, but this layer was not removed with such mean. To have a well stripped surface, an ashing-step in a $\mathrm{O}_{2}$ plasma oven before doing the wet etching step would be recommended. However for glassy carbon, that implies having a rough 
surface (micro-masking effect). Piranha etching (sulfuric acid mixed with hydrogen peroxide, ratio: 4:1, for 10min at $40^{\circ} \mathrm{C}$ ) has been performed and allowed us to remove part of the photoresist residues.

On the SEM pictures, we can see another drawback. The edges show sawtooth shapes instead of straight lines, and rounded corner instead of perpendicular corners. This kind of "wave effect" might be linked to the really low etching rate obtained. We were able to increase the beam intensity till a maximum etching rate of 24.3 and $48 \mathrm{~nm} / \mathrm{min}$ for GC and PR respectively (at $700 \mathrm{~V}$ and $1.1 \mathrm{~A}$ ). The selectivity between GC and PR is then about $1: 2$. Regarding the edges quality, the results are similar to the one observed in Figure 10. By comparison, using same etching beam parameters, hard materials such as TiW or AlTiC show low but in the same range etching rate, with 48 and $26 \mathrm{~nm} / \mathrm{min}$ respectively, and a wave effect may also appears after etching such material. That effect could be avoid by modifying the design on the photolithography mask and then being able to compensate such unwanted shape. However that it a demanding work, especially for high-resolution diffractive optical gratings design.

The Table I provides a summary of the results related to the four investigated process flows (A to D), including etching rate, selectivity and structure quality.

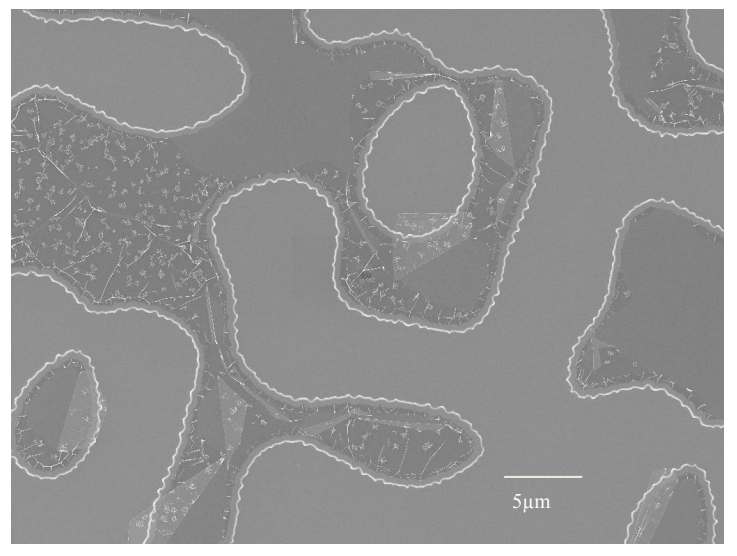

a)

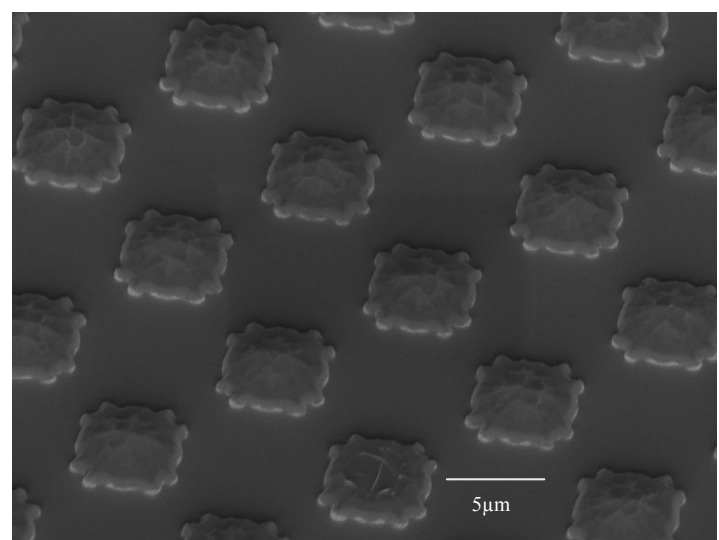

b)

Figure 10. SEM pictures of the GC structures after IBE and stripping. The structure shape shows an undesirable "wave effect", especially in the angles. GC stripping after IBE is hard to perform, then a few PR remains at the surface. GC depth is $331 \mathrm{~nm}$.

Table I. Results summary for the four investigated process flows (A to D).

\begin{tabular}{|c|c|c|c|c|}
\hline Process flow & $\mathbf{A}$ & B & $\mathbf{C}$ & D \\
\hline Description & PR mask, GC RIE & Al mask, GC RIE & Ti mask, GC RIE & PR mask, GC IBE \\
\hline Mask thickness [nm] & 2800 & $5(\mathrm{Ti})+300(\mathrm{Al})+5(\mathrm{Ti})$ & 500 & 1060 \\
\hline \multirow{2}{*}{ Etching rates $[\mathrm{nm} / \mathrm{min}]$} & PR: 540 & Al: 100 & Ti: $123-265$ & PR: $12(\max 24)$ \\
\hline & GC: 110 & GC: 230 & GC: 520 & GC: $30(\max 48)$ \\
\hline Selectivity (GC : mask) & $1: 5$ & $1: 0.4$ & $1: 0.2-0.5$ & $1: 2.5$ \\
\hline Related GC depth [nm] & 523 & 460 & $506-738$ & 331 \\
\hline Wall verticality $\left[{ }^{\circ}\right]$ & 37 & 67 & 79 & 61 \\
\hline GC roughness $\mathrm{RMS}_{\mathrm{a}}[\mathrm{nm}]$ & $<20$ & $<20$ & $<5$ & $<15$ \\
\hline Surface quality & High & Low (residues exist) & High & Low (residues exist) \\
\hline
\end{tabular}




\section{CONCLUSIONS}

We etched glassy carbon by reactive ion etching (process flow A, B and C) and by ion beam milling (process flow D) in section 2. Table 1 summarizes the results from section 3 related to etching rate, selectivity and structure quality. The photoresist-based processes (A and D) show an unfavorable etching ratio and lead to low edge definition. Aluminium hard masks cannot be used because of re-deposition of residues during the etching process of unknown constitution. Investigations are being done to clarify the cause of this problem. The third candidate to perform as a hard mask is titanium. Promising results could be obtained with this approach, as for example sharp edges or smooth surface. However titanium is not the preferred hard mask material because of its oxidation when exposed to air. Further characterizations are going to be done to understand this in more detail. Both aluminium and titanium have a smaller etching rate than glassy carbon which is preferential for high resolution and aspect ratio. The selectivity is 1:0.4 and 1:0.2-0.5 for $\mathrm{Al}$ and Ti respectively. This is much better than the 1:5 and 1:2.5 selectivity obtained between GC and photoresist using RIE and IBE. However an etching depth of $680 \mathrm{~nm}$ of GC still requires hard mask layers of over 300 $\mathrm{nm} \mathrm{Al}$ or $500 \mathrm{~nm} \mathrm{Ti}$. The hard mask layer thicknesses are too large to use lift-off processes for hard mask structuring; etching is needed instead. This makes the process flow complicated and more expensive.

\section{ACKNOWLEDGMENTS}

This research has been funded by the Commission for Technology and Innovation CTI under project number 12824.1 PFNM-NM. The authors thankfully acknowledge discussions with the partners from the ERANET-MNTGuide4Diffractive project, and the technical support from the Center of Micro-nanotechnology (CMI) at EPFL.

\section{REFERENCES}

[1] Gale, M. T., "Diffractive optics and micro-optics production technology in Europe," OSA Trends in Optics and Photonics (TOPS), Diffractive Optics and Micro-Optics, OSA Technical Digest 75, 18-20 (2002).

[2] Kress, B. C. and Meyrueis, P., [Applied Digital Optics, from Micro-Optics to Nanophotonics], John Wiley \& Sons, Chichester, UK (2009).

[3] Martinsson, H., Bengtsson, J., Ghisoni, M. and Larsson, A., "Monolithic Integration of Vertical-Cavity SurfaceEmitting Laser and Diffractive Optical Element for Advanced Beam Shaping," IEEE Photonics Technol. Letters 11(5), 503-505 (1999).

[4] Herzig, H. P., [Micro-Optics: Elements, Systems and Applications], Taylor \& Francis, London (1997).

[5] Ronggui, S. and Righini, G. C., "Characterization of reactive ion etching of glass and its applications in integrated optics," Journal of Vacuum Science \& Technology A 9, 2709 (1991).

[6] Iliescu, C., Jing, Ji., Tay, E. H.F., Miao, J. and Sun, T., "Characterization of masking layers for deep wet etching of glass in an improved HF/HCL solution," Surface \& Coatings Technol. 198, 314-318 (2005).

[7] Wang, M. R. and Su, H., "Laser direct-write gray-level mask and one-step etching for diffractive microlens fabrication," Applied Optics 37, 7568-76 (1998).

[8] Hirai, Y., Kanakugi, K., Yamaguchi, T., Yao, K., Kitagawa, S. and Tanaka, Y., "Fine pattern fabrication on glass surface by imprint lithography," Microelectron. Eng. 67-68, 237-244 (2003).

[9] Gan, J., Wang, X., Zhou, M., Ngoi, B. And Zhong, Z., "Ultraprecision diamond turning of glass with ultrasonic vibration," J. Adv. Manuf. Technol. 21, 952-955 (2003).

[10] Mertus, L. and Symmons, A., "Implications of diamond-turned vs diamond ground mold fabrication techniques on precision-molded optics," Proc. SPIE 8489 (2012).

[11] Behrmann, G. P. and Duignan, M. T., "Excimer laser micromachining for rapid fabrication of diffractive optical elements," Applied Optics 36(20), 4666-4674 (2007).

[12] Gale, M. T., "Replication techniques for diffractive optical elements," Microelectronic Engineering 34, 321-339 (1997).

[13] Gale, M. T., Gimkiewicz, C., Obi, S., Schnieper, M., Söchtig, J., Thiele, H. and Westenhöfer, S., "Replication technology for optical microsystems," Optics and Lasers in Engineering 43, 373-386 (2005).

[14] Yi, A. Y. and Jain, A., "Compression molding of aspherical glass lenses - A combined experimental and numerical analysis," J. Am. Ceram. Soc. 88(3), 579-586 (2005).

[15] Yi, A. Y., Chen, Y., Klocke, F., Pongs, G., Demmer, A., Grewell, A. And Benatar, A., "A high volume precision compression molding process of glass diffractive optics by use of a micromachined fused silica wafer mold and low $T_{g}$ optical glass,” J. Micromech. Microeng. 16(10), 2000-2005 (2006). 
[16] Komori, M., Uchiyama, H., Takebe, H., Kusura, T., Kobayashi, K., Kubawahara, H. and Tsuchiya, T., "Micro/nanoimprinting of glass under high temperature using a CVD diamond mold," J. Micromech. Microeng. 18, 065013 (2008).

[17] Yasui, M., Sugiyama, Y., Takahashi, M., Kaneko, S., Uegaki, J. I., Hirabayashi, Y., Sugimoto, K. I. and Maeda, R., "Fabrication of glassy carbon molds using hydrogen silsequioxane patterned by electron beam lithography as $\mathrm{O}_{2}$ dry etching mask," Jpn J of Appl. Phys. 47, 5167-5170 (2008).

[18] Choi, W., Lee, J., Kim, W.-B., Min, B.-K., Kang, S. and Lee, S.-J.,"Design and fabrication of tungsten carbide mould with micro patterns imprinted by micro lithography," J. Micromech. Microeng. 14, 1519-1525 (2004).

[19] Pang, S. W., Tamamura, T., Nakao, M., Ozawa, A. and Masuda, H., "Direct nano-printing on Al substrate using a SiC mold," J. Vac. Sci. Technol. B 16, 1145-1149 (1998).

[20] Itoh, T., Tanaka, S., Li, J.-F., Watanabe, R. and Esashi M., "Silicon-carbide microfabrication by silicon lost molding for glass-press molds," J. Microelectromech. Syst. 15(4), 859-863 (2006).

[21] He, P., Li, L., Yu, J., Huang, W., Yen, Y. C., Lee, L. J. and Yi, A. Y., "Graphene-coated Si mold for precision glass optics molding," Optics Letters 38(14), 2625-2628 (2013).

[22] Pettersson, U. and Jacobson, S., "Tribological texturing of steel surfaces with a novel diamond embossing tool technique," Tribol. Int. 39, 695-700 (2006).

[23] Hirai, Y., Yoshida, S., Takagi, n., Tanaka, Y., Yabe, H., Sasaki, K., Sumitani, H. and Yamamoto, K., "High aspect pattern fabrication by nano imprint lithography using fine diamond mold," Jpn. J. Appl. Phys. 42, 38633866 (2003).

[24] Takahashi, M., Sugimoto, K. and Maeda, R., "Nanoimprint of glass materials with glassy carbon molds fabricated by focused-ion-beam etching," Japan. J. Appl. Phys. 44, 5600-5605 (2005).

[25] Youn, S. W., Takahashi, M., Goto, H. and Maeda, R., "A study on fused ion beam milling of glassy carbon molds for the thermal imprinting of quartz and borosilicate glasses," J. Micromech. Microeng. 16, 2576-2584 (2006).

[26] Harris, P. J. F., "Fullerene-related structure of commercial glassy carbons," Philosophical Mag. 84:29, 31593167 (2004).

[27] Sasaki, T., Takahashi, M., Maeda, R., Tanaka, T., Maeno, T. and Yang, Z., "Microstructures formed on a low fluorescent glass using glassy carbon molding," Proc. IEEE, Eng. in Medicine and Biology $27^{\text {th }}$ Annual Conf., 7126-7128 (2005).

[28]Kuhnke, M., Lippert, Th., Ortelli, E., Scherer, G. G. and Wokaun, A., "Microstructuring of glassy carbon: comparison of laser machining and reactive ion etching," Thin Solid Films 453-454, 36-41 (2004).

[29] Ito, H., Ito, K., Arai, M., Sugimoto, K. I., Matsukura, T. and Kogai, T., "Wettability between glass-like carbon and optical glasses,” J. Jpn. Soc. Precision Eng., 70(6), 807-811 (2004).

[30] Youn, S. W., Takahashi, M., Goto, H. and Maeda, R., "Microstructuring of glassy carbon mold for glass embossing - Comparison of focused ion beam, nano/femtosecond-pulsed laser and mechanical machining," Microelectron. Eng. 83, 2482-2492 (2006).

[31] Youn, S. W., Takahashi, M., Goto, H. and Maeda, R., "Fabrication of micro-mold for glass embossing using focused ion beam, femto-second laser, excimer laser and dicing techniques," J. Mater. Process. Technol. 187188, 326-330 (2007).

[32] Takahashi, M., Murakoshi, Y., Maeda, R. and Hasegawa, K., "Large area micro hot embossing of pyrex glass with GC mold machined by dicing," Microsyst. Technol. 13, 379-384 (2007).

[33] Youn, S. W., Ueno, A., Takahashi, M. and Maeda, R., "A process of glassy carbon etching without the micro masking effect for the fabrication of a mold with a high-quality surface," J. Micromech. Microeng. 19, 125010 (2009).

[34] Mekaru, H., Okuyama, C., Ueno, A. and Takahashi, M., "Thermal imprinting on quartz fiber using glasslike carbon mold," J. Vac. Sci. Technol. B 27(6), 2820-2824 (2009).

[35] Ting, C.-C. and Chen, S.-Y., "Structural evolution and optical properties of $\mathrm{TiO}_{2}$ thin films prepared by thermal oxidation of sputtered Ti films," J. Appl. Phys. 88(8), 4628-4633 (2000).

[36] Fracassi, F. and Agostino, R. "Chemistry of titanium dry etching in fluorinated and chlorinated gases," Pure \& Appl. Chem. 64(5), 703-707 (1992). 